\title{
Canine mdr1 Gene Mutation in Japan
}

\author{
Akiko KAWABATA $^{1)}$, Yasuyuki MOMOI ${ }^{1) *}$, Miho INOUE-MURAYAMA ${ }^{2)}$ and Toshiroh IWASAKI ${ }^{1)}$ \\ ${ }^{1)}$ Department of Veterinary Internal Medicine, Faculty of Agriculture, Tokyo University of Agriculture and Technology, 3-5-8 Saiwai-cho, \\ Fuchu, Tokyo, 183-8509 and ${ }^{2}$ Laboratory of Animal Genetics, Department of Agricultural Science, Faculty of Applied Biological \\ Sciences, Gifu University, 1-1 Yanagido, Gifu 501-1193, Japan
}

(Received 24 February 2005/Accepted 7 July 2005)

ABSTRACT. Frequency of the 4-bp deletion mutant in canine $m d r l$ gene was examined in 193 dogs of eight breeds in Japan. The mutant allele was found in Collies, Australian Shepherds, and Shetland Sheepdogs, where its respective frequencies were 58.3\%, 33.3\%, and $1.2 \%$. The MDR1 protein was detected on peripheral blood mononuclear cells (PBMC) from a MDR1/MDR1 dog, but not on PBMC from a $m d r 1-1 \Delta m d r 1-1 \Delta$ Collie. Rhodamine 123 was extruded from MDR1/MDRl lymphocytes. That excretion was inhibited by a MDR1 inhibitor, verapamil. On the other hand, Rh123 excretion was not observed from lymphocytes derived from a $m d r 1-1 \Delta / m d r 1-$ $1 \Delta$ Collie. These results indicated that the mutant $m d r l$ allele also existed in Collie-breed dogs in Japan at high rates and that $m d r 1-1 \Delta$ /mdr1-1 $\Delta$ dogs have no functional MDR1.

KEY WORDS: canine, ivermectin, MDR1, mutation.

The MDR1 protein, also called P-glycoprotein, is a 170$\mathrm{kDa}$ membrane protein, a member of ATP-binding cassette (ABC) transporters that is encoded by the $m d r 1$ gene [11]. Regarding its role in multidrug resistance of tumor cells, MDR1 has been studied intensively [1, 2, 14, 17]. It is expressed not only in multidrug resistant tumor cells, but also in normal tissues such as the apical membrane of epithelial cells of the intestine and brain capillaries or in peripheral blood cells [3-6, 15, 32, 33]. A major physiological role of MDR1 is thought to be its function as an efflux pump of xenobiotics and cellular metabolites [3, 12].

Numerous single nucleotide polymorphisms (SNP) of $m d r l$ gene have been reported in humans. Some SNPs are inferred to be linked to its reduced function [8, 13, 22, 31]. In veterinary medicine, one polymorphism, 4-bp deletion mutation, was first reported in association with ivermectin sensitivity in Collies [21]. It has been found in several breeds among the herding group and sighthounds [18, 23]. Deletion generates a premature stop codon, thereby engendering prevention of synthesis of the complete MDR1 protein [21]. Frequency of the mutant $m d r 1$ allele in Collies has been reported as $51-64 \%$ in the United States, United Kingdom and France [10, 23]. Ivermectin, a MDR1 substrate, is a widely used parasiticide of the avermectin family. Many empirical cases of high sensitivity to ivermectin and experimental ivermectin-induced neurotoxicity have been reported among Collie-breed dogs [7, 25, 27]; the $m d r 1$ mutation was identified in some of these dogs [24]. It is believed that high sensitivity to ivermectin is at least partially attributable to the deletion of the $m d r l$ gene.

The MDR1 substrates include various drugs that are routinely used in veterinary medicine in addition to ivermectin.

\footnotetext{
* Correspondence to: Momoi, Y., Department of Veterinary Internal Medicine, Faculty of Agriculture, Tokyo University of Agriculture and Technology, 3-5-8 Saiwai-cho, Fuchu, Tokyo, 1838509 , Japan.
}

Possible toxicosis to other MDR1 substrate drugs including vincristine, vinblastine, doxorubicin, and loperamide, has been reported in relation to the $m d r l$ gene mutation [20, 29]. This study examined the frequency of the $m d r l$ mutant allele in a Japanese population of eight breeds including Collie. Using peripheral blood mononuclear cells from a Collie having homozygous $m d r 1$ mutant allele, MDR1 protein expression and its function were assessed.

\section{MATERIALS AND METHODS}

DNA amplification of canine mdrl gene: DNA samples were obtained from 192 client-owned dogs and a Collie that had been housed at our facility. The breeds included Collie, Australian Shepherd, Shetland Sheepdog and five other popular breeds in Japan: Labrador Retriever, Golden Retriever, Shih Tzu, Shiba Inu, and Dachshund. A venous blood sample was collected from each dog for genomic DNA extraction. The DNA was extracted using a PAXgene Blood DNA Kit (Qiagen GmbH, Hilden, Germany) or a QIAamp DNA Blood Mini Kit (Qiagen $\mathrm{GmbH}$ ), depending on the amount of the blood sample. For PCR reactions, 500 $\mathrm{nM}$ of each primer at final concentration, $0.05-1.56 \mu \mathrm{g}$ of extracted DNA, and $12.5 \mu l$ of PCR Master Mix (Promega Corp., Madison, WI) were used. The total volume was adjusted to $25 \mu l$ with nuclease-free water. The primers were designed to amplify 60-bp DNA fragments of the wild type allele, which encompasses the putative deletion site [28] (GenBank AF045016). Nucleotide sequences of the primers were 5'-CCTCTCATGATGCTGGT (forward primer) and 5'-TGAAATTCCTGCATTTGCA (reverse primer). The PCR condition was: initial denaturation at $94^{\circ} \mathrm{C}$ for $2 \mathrm{~min} ; 30$ cycles consisting of denaturation at $94^{\circ} \mathrm{C}$ for $1 \mathrm{~min}$; annealing at $56.2^{\circ} \mathrm{C}$ for $1 \mathrm{~min}$; and extension at $72^{\circ} \mathrm{C}$ for $1 \mathrm{~min}$; then extra extension at $72^{\circ} \mathrm{C}$ for $1 \mathrm{~min}$. The PCR products were electrophoresed in 5\% agarose gels $/ 0.5$ 
$\times$ Tris-Borate EDTA buffer. The DNA bands were stained with ethidium bromide following electrophoresis and were visualized using a UV-transilluminator.

$M D R 1$ protein expression on canine PBMC: Anti-human MDR1 monoclonal antibody JSB-1, which has been shown to react to canine MDR1 [5], was used to assess the expression of MDR1 protein on canine PBMC. Peripheral venous blood samples were obtained from a $m d r 1-1 \Delta / m d r 1-1 \Delta$ Collie and a mixed-breed dog that was homozygous for the normal $m d r 1$ allele (a MDR $1 / M D R 1$ dog). The PBMC were collected through density centrifugation with a Histopaque $^{\circledR}-1077$ (Sigma-Aldrich Corp., St. Louis, MO). The cells were washed twice with cold phosphate buffered saline (PBS) $/ 1 \%$ fetal bovine serum (FBS). Then the cells were fixed with $70 \%$ methanol at room temperature for $1 \mathrm{~min}$ and washed twice with PBS/1\%FBS. The cells were suspended in $30 \mu l$ of 1:10 diluted anti-human antibody JSB-1 (Kamiya Biomedical Co., Seattle, WA) and incubated at $4{ }^{\circ} \mathrm{C}$ for 30 $\mathrm{min}$. The cells were then washed three times with cold PBS/ $1 \% \mathrm{FBS}$ and reacted with $5 \mu \mathrm{g} / \mathrm{m} l$ of FITC-conjugated goat $\left.\mathrm{F}(\mathrm{ab})^{\prime}\right)_{2}$ anti-mouse $\operatorname{IgG}(\mathrm{H}+\mathrm{L})$ (SouthernBiotech, Birmingham, AL) at $4^{\circ} \mathrm{C}$ for $30 \mathrm{~min}$. The cells were washed three times with cold $\mathrm{PBS} / 1 \% \mathrm{FBS}$, resuspended in cold $\mathrm{PBS} / 1 \%$ FBS, and 20,000 cells were analyzed by flow cytometry (CyFlow; Ikeda Scientific Co., Ltd., Tokyo, Japan). As a control, cells were incubated with FITC-conjugated goat anti-mouse IgG antibody without primary antibody.

Rhodamine 123 efflux assay: Rhodamine 123 was used for fluorescence dye efflux assays [6, 9, 10, 26]. Verapamil hydrochloride (VRP) was used as a P-gp inhibitor [9, 34]. Verapamil concentration was determined by preparatory assay to have no cytotoxic effect on PBMC. The PBMC were collected from the $m d r 1-1 \Delta / m d r l-1 \Delta$ Collie and a MDRl/MDRl dog. The PBMC $\left(1 \times 10^{5} / \mathrm{m} l\right)$ were incubated with $150 \mathrm{ng} / \mathrm{ml}$ of Rh123 (Wako Pure Chemical Industries Ltd., Osaka, Japan) with or without $1 \mu \mathrm{g} / \mathrm{m} l$ of verapamil (Sigma-Aldrich Corp., St. Louis, MO) at $37^{\circ} \mathrm{C}$ for $30 \mathrm{~min}$. After washing twice with cold PBS/1\%FBS, the control sample for the dye uptake baseline was kept on ice until analysis. All other samples were resuspended in Rh123 free $\mathrm{PBS} / 1 \% \mathrm{FBS}$ and incubated at $37^{\circ} \mathrm{C}$ for $90 \mathrm{~min}$ to allow dye efflux. After incubation, samples were washed twice with cold PBS/1\%FBS; then, fluorescence intensity of the cells was analyzed using flow cytometry. Lymphocyte populations were selected for analysis using forward scatter (FSC) and side scatter (SSC) dot plots. Thereby, approximately 5,000 lymphocytes were assessed.

\section{RESULTS}

Frequency of the mutant mdrl allele: DNA samples obtained from 193 dogs of eight breeds were tested for the $m d r l$ gene mutation. The two different bands-one of which was 60-bp fragment of the normal $m d r 1$ allele and the other of which was 56-bp fragment of the mutant $m d r 1$ allele - were comparably distinguished on 5\% agarose gels (Fig. 1). The nucleotide sequence of a $m d r 1-1 \Delta$ allele from a Collie predicted to be $m d r 1-1 \Delta / m d r 1-1 \Delta$ showed an identical mutation to one that was already reported to be associated with ivermectin sensitivity in Collies (data not shown).

The 4-bp deletion mutation of $m d r l$ gene was detected in three collie-breeds: Collie, Australian Shepherd, and Shetland Sheepdog. The deletion was not found in five other breeds (Table 1). Of the 12 Collies, 5 (41.7\%) were homozygous for the mutant allele $(m d r 1-1 \Delta m d r 1-1 \Delta)$, and $4(33.3 \%)$ were heterozygous $(m d r l-1 \Delta M D R l)$. Of the 9 Australian Shepherds, 1 (11.1\%) was $m d r 1-1 \Delta m d r 1-1 \Delta$, and $4(44.4 \%)$ were $m d r 1-1 \Delta / M D R 1$. Among Shetland Sheepdogs, 1 (2.4\%) was $m d r 1-1 \triangle / M D R 1$.

$M D R 1$ protein expression on canine PBMC: Expression of MDR1 protein on canine PBMC was analyzed using anti-human P-gp monoclonal antibody, JSB-1 (Fig. 2). Expression of MDR1 was detected on PBMC from a MDR1/ $M D R 1$ dog. In contrast, MDR1 protein was not detected on

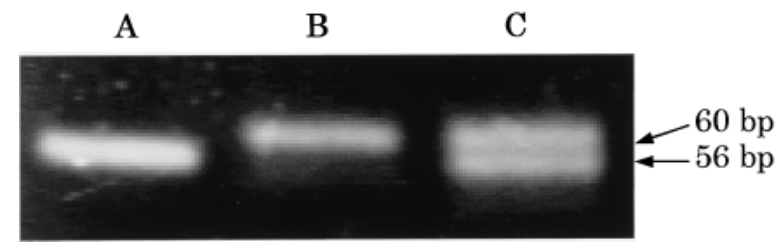

Fig. 1. Canine $m d r l$ gene was amplified from genomic DNA from 193 dogs. PCR products were electrophoresed in 5\% agarose gel. Representative cases are shown. Lane A, a 56-bp band was detected from a $m d r 1-1 \Delta m d r 1-1 \Delta$ Collie; B, a 60-bp band was detected from a MDR1/MDR1 Shih Tzu; C, a 60-bp band and a 56-bp band were detected from a $m d r 1-1 \Delta M D R 1$ Australian Shepherd.

Table 1. Frequency of the $m d r l$ mutation in 193 dogs of 8 breeds in Japan

\begin{tabular}{lccccc}
\hline & $\mathrm{n}$ & MDR1/MDRI & mdr1-1 1 MDR1 & mdr1-1 1 mdr1-1 & Mutantallele frequency \\
\hline Collie & 12 & $3(25.0 \%)$ & $4(33.3 \%)$ & $5(41.7 \%)$ & $58.3 \%$ \\
Australian Shepherd & 9 & $4(44.4 \%)$ & $4(44.4 \%)$ & $1(11.1 \%)$ & $33.3 \%$ \\
Shetland Sheepdog & 42 & $41(97.6 \%)$ & $1(2.4 \%)$ & $0(0.0 \%)$ & $1.2 \%$ \\
Labrador Retriever & 37 & $37(100.0 \%)$ & $0(0.0 \%)$ & $0(0.0 \%)$ & $0.0 \%$ \\
Golden Retriever & 28 & $28(100.0 \%)$ & $0(0.0 \%)$ & $0(0.0 \%)$ & $0.0 \%$ \\
Shih Tzu & 37 & $37(100.0 \%)$ & $0(0.0 \%)$ & $0(0.0 \%)$ & $0.0 \%$ \\
Shiba Inu & 21 & $21(100.0 \%)$ & $0(0.0 \%)$ & $0(0.0 \%)$ & $0.0 \%$ \\
Dachshund & 7 & $7(100.0 \%)$ & $0(0.0 \%)$ & $0(0.0 \%)$ & $0.0 \%$ \\
\hline
\end{tabular}


(A)

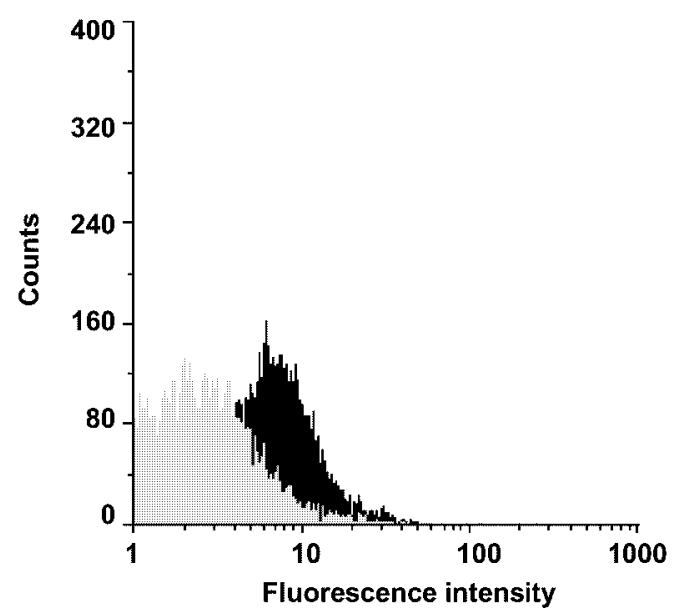

(B)

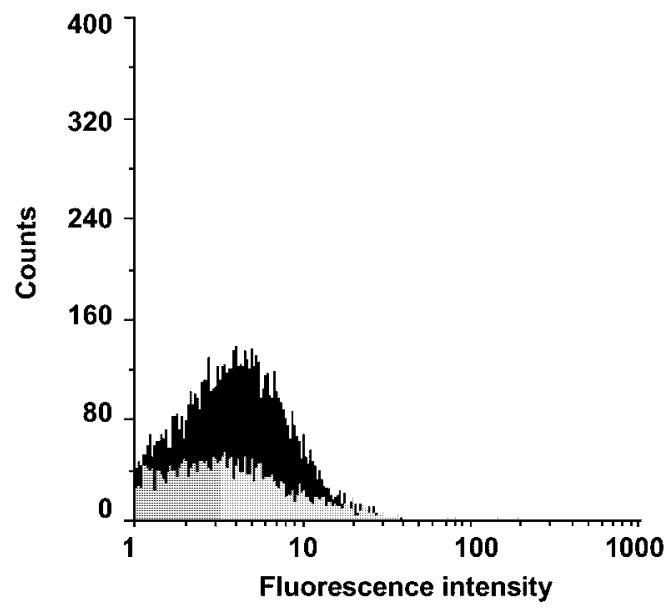

Fig. 2. MDR1 protein expression on canine PBMC analyzed by flow cytometry with monoclonal antibody, JSB-1. Gray-filled histograms are negative controls without primary antibody, and black-filled histograms show expressions of MDR1 protein. (A) Expression of MDR1 on PBMC from a MDR1/MDR1 dog. (B) Expression of MDR1 on PBMC from a $m d r 1-1 D / m d r 1-1 D$ Collie. For visual decreased numbers of PBMC were represented in negative controls.

(A)

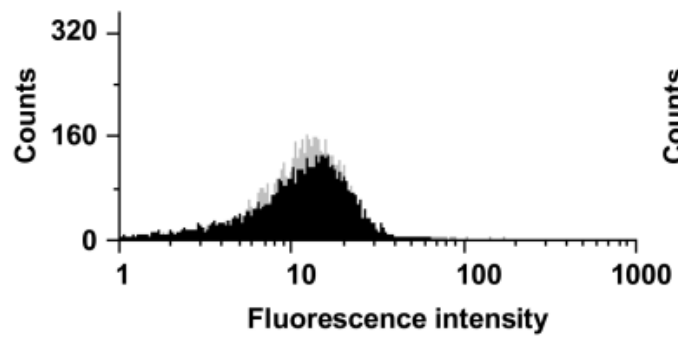

(B)

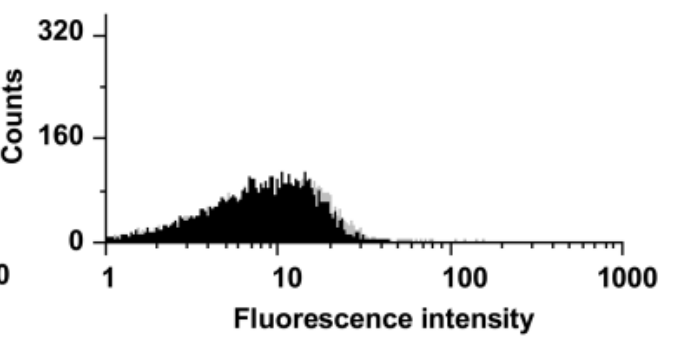

Fig. 3. Rh123 efflux from canine lymphocytes was measured using flow cytometry. PBMC were incubated with Rh123 in the presence or absence of VRP. Fluorescence intensity in lymphocytes was measured after 90-min efflux. The histograms represent Rh123 fluorescence intensity in gated lymphocytes. Gray-filled histograms represent intensity in lymphocytes incubated with VRP. Black-filled histograms represent intensity in lymphocytes incubated without VRP. (A) Fluorescence intensity in lymphocytes from a MDR1/MDR1 dog. (B) Fluorescence intensity in lymphocytes from a $m d r 1-1 \Delta / m d r 1-1 \Delta$ Collie.

PBMC from a $m d r 1-1 \Delta / m d r 1-1 \Delta$ Collie.

Rhodamine 123 efflux assay: MDR1 function of peripheral blood lymphocytes was assessed using fluorescence dye efflux assays. The PBMC were incubated with Rh123 in the presence or absence of VRP; fluorescence intensity in lymphocytes was assessed (Fig. 3). The respective median fluorescence intensities after efflux in MDR $1 / M D R 1$ lymphocytes incubated with or without VRP were $78.8 \%$ and $67.4 \%$ of that before efflux, whereas the respective median fluorescence intensities in $m d r 1-1 \Delta / m d r 1-1 \Delta$ lymphocytes incubated with or without VPR were $99.5 \%$ and $95.9 \%$ of that before efflux.

\section{DISCUSSION}

This study found 4-bp deletion of $m d r l$ gene in a Japanese population of three collie-breeds that are reported to have the mutant allele [23]. In Collies, the frequency of the mutant allele was $58.3 \%$; about three-fourths of the Collie population were either homozygous or heterozygous for the mutant allele. Australian Shepherds showed a high frequency of the mutant allele. Among Shetland Sheepdogs, only one dog had the mutant allele as heterozygous. Although few dogs were examined in this study, these results correspond to previous reports about the frequency of the mutant allele in United States, United Kingdom and 
Australia [10, 23]. The mutant allele was not found in this study in the other five breeds including Labrador Retriever, Golden Retriever, Shih Tzu, Shiba Inu, and Dachshund. The $m d r 1$ mutation has not been reported in those breeds so far. For that reason, the frequency of the mutant allele is inferred to be low in those five breeds [23].

The MDR1 expression on human peripheral blood cells, including lymphocytes, has been demonstrated [3, 4, 6, 15]. In this study, expression of MDR1 was detected on PBMC from a $M D R 1 / M D R 1$ dog, but not on PBMC from a $m d r 1-$ $1 \Delta / m d r 1-1 \Delta$ Collie. Messenger RNA expression of the deleted $m d r-1$ gene was detected in PBMC from a $m d r 1-1 \Delta$ $m d r 1-1 \Delta$ Collie(data not shown). The functional MDR1 protein might not be expressed on any type of cells in $m d r 1-$ $1 \Delta m d r 1-1 \Delta$ dogs because the 4-bp deletion generates an early stop codon.

Fluorescence dye efflux assays were carried out to assess MDR1 functions of canine PBMC. The Rh123 excretion from $M D R 1 / M D R 1$ lymphocytes was inhibited by $1 \mathrm{mg} / \mathrm{m} l$ of VRP. In $m d r 1-1 \Delta / m d r 1-1 \Delta$ lymphocytes, excretion of Rh123 was negligible both in the presence and absence of VRP. These results indicated that MDR1 that is expressed on canine PBMC functions in excretion of xenobiotics, which is consistent with a previous report describing overcoming of vincristine resistance by $1.1 \mu \mathrm{g} / \mathrm{m} l$ of VRP in leukemic cells [34].

Not only is MDR1 related to a multidrug resistance state in cancer patients; it is possibly related to adverse effects of anticancer drugs in canine cancer patients [20]. Some anticancer drugs, including vincristine, vinblastine, and doxorubicin, are substrates of MDR1 protein [30]. Sensitivity to vincristine was examined using phytohemagglutinin-stimulated PBMC from a $m d r 1-1 \Delta / m d r 1-1 \Delta$ dog (data not shown). Although the PBMC showed no high sensitivity to vincristine compared to MDR1/MDR1 PBMC, anticancer drugs should be administered carefully to $m d r 1-1 \Delta / m d r 1-$ $1 \Delta$ dogs $[19,21]$.

The MDR1 genotypes also give an indication for the use of avermectins including ivermectin and doramectin. Its administration to Collie-breed-dogs should be avoided, especially to Collies and Australian Shepherds [35]. Nevertheless, much information regarding the relationship between drug sensitivity and $m d r l$ genotypes remains unknown. Further investigation of other mutations of $m d r l$ gene or drug sensitivity of $m d r 1-1 \Delta / M D R 1$ dogs will be pharmacogenetically instructive for the adequate use of MDR1-substrate drugs.

\section{REFERENCES}

1. Arceci, R. J. 1993. Clinical significance of P-glycoprotein in multidrug resistance malignancies. Blood 81: 2215-2222.

2. Campos, L., Guyotat, D., Archimbaud, E., Calmard-Oriol, P., Tsuruo, T., Troncy, J., Treille, D. and Fiere, D. 1992. Clinical significance of multidrug resistance P-glycoprotein expression on acute nonlymphoblastic leukemia cells at diagnosis. Blood 79: $473-476$

3. Drach, D., Zhao, S., Drach, J., Mahadevia, R., Gattringer, C.,
Huber, H. and Andreeff, M. 1992. Subpopulations of normal peripheral blood and bone marrow cells express a functional multidrug resistant phenotype. Blood 80: 2729-2734.

4. Drach, J., Gsur, A., Hamilton, G., Zhao, S., Angerler, J., Fiegl, M., Zojer, N., Raderer, M., Haberl, I., Andreeff, M. and Huber, H. 1996. Involvement of P-glycoprotein in the transmembrane transport of Interleukin-2 (IL-2), IL-4, and Interferon- $\gamma$ in normal human T lymphocytes. Blood 88: 1747-1754.

5. Ginn, P. E. 1996. Immunohistochemical detection of P-glycoprotein in formalin-fixed and paraffin-embedded normal and neoplastic canine tissues. Vet. Pathol. 33: 533-541.

6. Gupta, S., Kim, C. H., Tsuruo, T. and Gollapudi, S. 1992. Preferential expression and activity of multidrug resistance gene 1 product (P-glycoprotein), a functionally active efflux pump, in human CD8+ T cells: a role in cytotoxic effector function. $J$. Clin. Immunol. 12: 451-458.

7. Hadrick, M. K., Bunch, S. E. and Kornegay, J. N. 1995. Ivermectin toxicosis in two Australian shepherds. J. Am. Vet. Med. Assoc. 206: 1147-1152.

8. Hoffmeyer, S., Burk, O., von Richter, O., Arnold, H. P., Brockmöller, J., Jojne, A., Cascorbi, I., Gerloff, T., Roots, I., Eichelbaum, M. and Brinkmann, U. 2000. Functional polymorphisms of the human multidrug resistance gene: Multiple sequence variations and correlation of one allele with P-glycoprotein expression and activity in vivo. Proc. Natl. Acad. Sci. U.S.A. 97: 3473-3478.

9. Huet, S., Marie, J.- P., Gualde, N. and Robert, J. 1998. Reference method for detection of Pgp mediated multidrug resistance in human hematological malignancies: a method validated by the laboratories of the French Drug Resistance Network. Cytometry 34: 248-256.

10. Hugnet, C., Bentjen,S. A. and Mealey, K. L. 2004. Frequency of the mutant MDR1 allele associated with multidrug sensitivity in a sample of collies from France. J. Vet. Pharmacol. Ther. 27: 227-229.

11. Hyde, S. C., Emsley, P., Hartshorn, M. J., Mimmack, M. M., Gileadi, U., Pearce, S. R., Gallagher, M. P., Gill, D. R., Hubbard, R. E. and Higgins, C. F. 1990. Structural model of ATPbinding proteins associated with cystic fibrosis, multidrug resistance and bacterial transport. Nature (Lond.) 346: $312-$ 313.

12. Juliano, R. L. and Ling, V. 1976. A surface glycoprotein modulating drug permeability in Chinese hamster ovary cell mutants. Biochim. Biophys. Acta 455: 152-162.

13. Kimchi-Sarfaty, C., Gribar, J. J. and Gottesman, M. 2002. Functional characterization of coding polymorphisms in the human MDR1 gene using a vaccinia virus expression system. Mol. Pharmacol. 62: 1-6.

14. Leveille-Webster, C. R. and Arias, I. M. 1995. The biology of the P-glycoproteins. J. Membr. Biol. 143: 89-102.

15. Ludescher, C., Pall, G., Irschick, E. U. and Gastl, G. 1998. Differential activity of P-glycoprotein in normal blood lymphocyte subsets. Br. J. Haematol. 101: 722-727.

16. Mackenzie, C. D., Geary, T. G. and Gerlach, J. A. 2003. Possible pathogenic pathways in the adverse clinical events seen following ivermectin administration to onchocerciasis patients. Filaria J. 2 (Suppl. 1): S5.

17. Marie, J.- P., Zittoun, R. and Sikic, B. I. 1991. Multidrug resistance $(m d r l)$ gene expression in adult acute leukemias: correlations with treatment outcome and in vitro drug sensitivity. Blood 78: 586-592.

18. Mealey, K. L. 2004. A new tool that detects ivermectin and other drug sensitivities in dogs. Vet. Med. 99: 419-426. 
19. Mealey, K. L. 2004. Therapeutic implications of the MDR-1 gene. J. Vet. Pharmacol. Ther. 27: 257-264.

20. Mealey, K. L., Northrup, N. C. and Bentjen, S. A. 2003. Increased toxicity of P-glycoprotein substrate chemotherapeutic agents in a dog with the MDR1 deletion mutation associated with ivermectin sensitivity. J. Am. Vet. Med. Assoc. 223: 14531455.

21. Mealey, K. L., Bentjen, S. A., Gay, J. M. and Cantor, G. H. 2001. Ivermectin sensitivity in collies is associated with a deletion mutation of the mdr1 gene. Pharmacogenetics 11: 727733.

22. Nakamura, T. 2003. MDR1 genotypes related to Pharmacokinetics and MDR1 expression. Yakugaku Zasshi 123: 773-779 (in Japanese).

23. Neff, M. W., Robertson, K. R., Wong, A. K., Safra, N., Broman, K. W., Slatkin, M., Mealey, K. L. and Pedersen, N. C. 2004. Breed distribution and history of canine $m d r 1-1 \Delta$, a pharmacogenetic mutation that marks the emergence of breeds from the collie lineage. Proc. Natl. Acad. Sci. U.S.A. 101: $11725-11730$.

24. Nelson, O. L., Carsten. E., Bentjen, S. A. and Mealey, K. L. 2003. Ivermectin toxicity in an Australian shepherd dog with the MDR1 mutation associated with ivermectin sensitivity in collies. J. Vet. Intern. Med. 17: 354-356.

25. Paul, A. J., Tranquilli, W. J., Seward, R. L., Todd, K. S. and DiPietro, J. A. 1987. Clinical observations in Collies given ivermectin orally. Am. J. Vet. Res. 48: 684-685

26. Pétriz, J. and García-López, J. 1997. Flow cytometric analysis of P-glycoprotein function using rhodamine 123. Leukemia 11: 1124-1130.

27. Pulliam, J. D., Seward, R. L., Henry, R. T. and Steinberg, S. A. 1985. Investigating ivermectin toxicity in collies. Vet. Med. 7: 33-40.
28. Roulet, A., Puel, O., Gesta, S., Lepage, J.- F., Drag, M., Soll, M., Alvinerie, M. and Pineau, T. 2003. MDR1-deficient genotype in Collie dogs hypersensitive to the P-glycoprotein substrate ivermectin. Eur. J. Pharmacol. 460: 85-91.

29. Schinkel, A. J., Wagenaar, E., Mol, C. A. A. M. and van Deemter, L. 1996. P-glycoprotein in the blood-brain barrier of mice influence the brain penetration and pharmacological activity of many drugs. J. Clin. Invest. 97: 2517-2524.

30. Sartor, L. L., Bentjen, S. A., Trepanier, L. and Mealey, K. L. 2004. Loperamide toxicity in a collie with the MDR1 mutation associated with ivermectin sensitivity. J. Vet. Intern. Med. 18: $117-118$.

31. Siegmund, W., Ludwig, K., Giessmann, T., Dazert, P., Schroeder, E., Sperker, B., Warzok, R., Kromer, H. K. and Cascorbi, I. 2002. The effects of the human MDRl genotype on the expression of duodenal P-glycoprotein and disposition of the probe drug talinolol. Clin. Pharmacol. Ther. 72: 572-583.

32. Thiebaut, F., Tsuruo, T., Hamada, H., Gottesman, M. M., Pastan, I. and Willingham, M. C. 1987. Cellular localization of the multidrug-resistance gene product $\mathrm{P}$-glycoprotein in normal human tissues. Proc. Natl. Acad. Sci. U.S.A. 84: 77357738 .

33. Trambas, C., Wang, Z., Cianfriglia, M. and Woods, G. 2001. Evidence that natural killer cells express mini P-glycoproteins but not classic 170 kDa P-glycoprotein. Br. J. Haematol. 114: $177-184$

34. Tsuruo, T., Iida, H., Tsukagoshi, S. and Sakurai, Y. 1981. Overcoming of vincristine resistance in P388 leukemia in vivo and in vitro through enhanced cytotoxicity of vincristine and vinblastine by verapamil. Cancer Res. 41: 1967-1972.

35. Yas-Natan, E., Shamir, M., Kleinbart, S. and Aroch, I. 2003. Doramectin toxicity in a collie. Vet. Rec. 153: 718-720. 